\title{
Elaboración de videos didácticos: un espacio para el aprendizaje activo
}

\author{
Claudia A. TRONCOSO-PANTOJA, Fredy DÍAZ-AEDO, Juan P. AMAYA-PLACENCIA, Susana PINCHEIRA-AGUILERA
}

En la actualidad, se identifica que el uso de herramientas tecnológicas es un factor innegable para el incremento de la motivación y, sobre todo, del aprendizaje en estudiantes de educación superior [1,2]. El empleo de tecnologías de la información y la comunicación permite la organización de contenidos educacionales entregados en cátedras u otras actividades pedagógicas, favoreciendo la retroalimentación entre los actores del proceso de formación profesional y permitiendo, a la vez, su reutilización acorde con las necesidades académicas del estudiante [3].

Las actuales generaciones son reconocidas como nativos digitales, ya que incorporan la información multimedia, desde imágenes y videos, a su estrategia didáctica de aprendizaje en reemplazo de los textos tradicionales [4], y presentan una mayor predisposición a utilizar las tecnologías y los entornos digitales en actividades de experiencia educativa y de aprendizaje [5]. Es por esto que los videos educativos surgen como una herramienta eficaz para el proceso de enseñanza-aprendizaje activo a través de la entrega de información y la promoción de la participación de los estudiantes en su formación profesional [6].

La necesidad de potenciar el aprendizaje activo de estudiantes universitarios es la base de la innovación educativa, que tiene como objetivo principal la elaboración de videos educativos como recurso de aprendizaje en la práctica educativa de estudiantes de la carrera de nutrición y dietética de la Universidad Católica de la Santísima Concepción (UCSC), en Concepción, Chile.

La innovación académica surge del proyecto docente con financiación institucional denominado 'Videos docentes para el aprendizaje activo de estudiantes de nutrición y dietética de la UCSC, que en su primera etapa presenta como fin último la realización de videos educativos para que puedan usarse en el fortalecimiento de aprendizajes previos, el reforzamiento de contenidos o la evaluación de aprendizajes.

La elaboración de videos se realiza en cuatro etapas, que incluyen el análisis de la situación, el cual se realiza a través de un diagnóstico participativo con 37 estudiantes de la carrera a los que se interroga mediante un cuestionario de pregunta abierta: ¿qué contenidos quisieras que se profundizaran mediante un video?'. Las respuestas entregadas permitieron seleccionar contenidos que necesitaban ser ahondados en su opinión y que fueron considerados por el equipo ejecutor para la delimitación de los mensajes didácticos a través de los videos. La etapa del diseño incluía, por una parte, la elaboración del guion, y consideraba título del video, autor, actividad curricular al que tributaba, tema a tratar, objetivo, contenidos, destinatarios, tipo de video y descripción de la secuencia de este último. El diseño consideraba también la selección del video a utilizar, que podía ser un tutorial realizado por el docente, el uso de PowerPoint o el del programa Vyond para realizar animaciones con contenido didáctico del área de nutrición y dietética.

La fase de producción de los videos se concretó en el Laboratorio de Biología Interactiva (Bilab), espacio propio de la Facultad de Medicina que dispone de recursos tecnológicos para el desarrollo de un ambiente creativo que permite la creación de objetos digitales animados e interactivos. Esta actividad estuvo a cargo de un diseñador gráfico, quien realizó las acciones de ejecución y edición de los videos. Una vez finalizados, los videos estuvieron disponibles en el canal YouTube del Bilab de la UCSC y en la plataforma Moodle institucional, para su utilización por los estudiantes en una fase preliminar como parte de su aprendizaje autónomo.

Como conclusión del proceso de elaboración de los videos, la fase de evaluación se realizó a través de un cuestionario de opinión por parte de informantes claves, referido a estudiantes $(n=10)$ y académicos de la carrera $(n=10)$, y que profundizaba en los aspectos funcionales del video, el contenido y su cumplimiento de metas o resultados de aprendizaje de la actividad académica. También se midieron los aspectos pedagógicos del video, en donde se profundizaba si los contenidos y actividades incluidos eran acordes con el grupo a educar, si su organización y resumen de la información eran adecuados, y si se lograba captar el interés del grupo diana. También se ahondó en los aspectos estéticos, solicitando la opinión sobre las imágenes, gráficos o ani-
Centro de Investigación en Educación y Desarrollo (C.A. Troncoso-Pantoja). Facultad de Medicina (C.A. TroncosoPantoja, F. Díaz-Aedo, J.P. AmayaPlacencia, S. Pincheira-Aguilera). Universidad Católica de la Santísima Concepción. Concepción, Chile.

Correspondencia:

Dra. Claudia A. Troncoso Pantoja. Facultad de Medicina. Universidad Católica de la Santísima Concepción. Campus San Andrés. Alonso de Ribera, 2850. Concepción, Chile.

E-mail:

ctroncosop@ucsc.cl

Financiación:

Proyecto FAD 21/2018. Dirección de Docencia, Universidad Católica de la Santísima Concepción, Chile.

(c) 2019 FEM 
maciones, la banda sonora (voces o música) y el planteamiento audiovisual (interacción entre elementos). Por último, se evaluó el texto del video, preguntando sobre los contenidos (calidad, profundidad u organización) y la estructura y ritmo, claridad del guion y adecuada secuencia. Complementa la evaluación de los videos el registro de visitas que dejó la red social YouTube.

Se realizaron un total de siete videos didácticos, además de un tutorial destinado al traspaso de presentaciones de PowerPoint a video mediante el programa OBS Studio en su versión gratuita.

El diagnóstico participativo realizado a los estudiantes reflejó un interés por reforzar contenidos del manejo dietético de lactantes, así como de actividades propias de la disciplina, como es la determinación de requerimientos de energía y nutrientes y las medidas caseras de algunos alimentos.

Por otra parte, la encuesta de opinión realizada a estudiantes y docentes de la carrera presenta el 95\% de opinión como buena o muy buena para los aspectos pedagógicos y texto de los videos. En los aspectos funcionales, el $90 \%$ exhibe también un parecer positivo, así como el $85 \%$ a las características de animación de estos últimos. Por otra parte, la totalidad de los encuestados tiene una opinión positiva sobre el texto de los videos. En cuanto a las vistas en el canal de YouTube, el video más visitado fue el tutorial destinado a traspasar presentaciones en PowerPoint a videos mediante OBS Studio, con un total de 391 vistas entre octubre de 2018 y enero 2019.

La elaboración de medios audiovisuales como los videos didácticos son un aporte a la formación profesional de nuestros estudiantes, al actuar como un canal facilitador en la entrega de contenidos, pero también favorecer el aprendizaje activo e incrementar la creatividad del docente y su forma de comunicar las temáticas disciplinares. El uso de los videos como estrategia de formación pedagógica y herramienta educativa es reconocida y utilizada en el proceso de enseñanza y aprendizaje de estudiantes y profesionales en distintas disciplinas del área de la salud, identificando beneficios en su uso como una mejor adquisición de conocimientos sobre una determinada temática, un preferible desempeño operativo y una mayor satisfacción por parte de los usuarios de esta herramienta digital [7].

La elaboración de los videos requirió una instancia de planificación y elaboración formal e inclusiva con estudiantes y docentes, permitiendo de esta manera el cumplimiento de sus metas finales. También se observó la necesidad de que un video presente un ordenamiento lógico en su construcción, accediendo a un mayor acercamiento a los estudiantes y permi- tiendo que las imágenes sean contenidos de aprendizaje por sí mismos [8]. Esto último fue reconocido por los beneficiarios de esta innovación docente, quienes en su mayoría presentan una opinión positiva de los aspectos formales y técnicos de los videos.

Para difundir la información y conocimiento, los videos requieren canales de trasmisión. Nuestra innovación utilizó las plataformas Moodle institucional (cerrado) y YouTube (libre acceso) como herramientas de educación virtual, lo que facilita el aprendizaje activo de los estudiantes. El uso del portal YouTube se basa en el reconocimiento de esta red social como 'amistosa' hacia la audiencia, facilita la entrega de contenidos y, cuando se presenta una formalización en su entrega, permite concretar logros en un grupo objetivo [9].

El uso eficiente de los videos se fortalece si se considera en su elaboración la carga cognitiva que aporta, pero también el compromiso de los estudiantes con su uso y su aprendizaje activo a través de esta herramienta tecnológica [10]. Nuestra innovación fue el inicio del trabajo con videos didácticos. Comienza ahora su implementación, con planificaciones para el trabajo académico, permitiendo su uso en el fortalecimiento de aprendizajes previos, el reforzamiento de contenidos o la evaluación de aprendizajes.

\section{Bibliografía}

1. Zúñiga M, Ferri G, Baltera C. Evaluación de la motivación académica tras implementar simulación háptica en estudiantes de primer año de la Universidad San Sebastián, en Santiago de Chile. FEM 2018; 21: 137-41.

2. Saavedra F, Saavedra L. Entorno virtual Moodle en la mejora del aprendizaje de cirugía en estudiantes de medicina de la Universidad Católica Santo Toribio de Mogrovejo. FEM 2017; 20: 241-6.

3. Zambrano J, Arango L, Lezcano M. Estilos de aprendizaje, estrategias de aprendizaje y su relación con el uso de las TIC en estudiantes de educación secundaria. Journal of Learning Styles 2018; 11: 130-59.

4. González S, Triviño M. Las estrategias didácticas en la práctica docente universitaria. Profesorado, Revista de currículum y formación del profesorado 2018; 22: 371-88.

5. Alcalde-Fierro MJ. Reflexión acerca del ejercicio audiovisual como medio de expresión del diseño gráfico experimental. Centro de Estudios en Diseño y Comunicación 2018; 66: 25-39.

6. Brame CJ. Effective educational videos. 2015. URL: https://cft. vanderbilt.edu/guides-sub-pages/effective-educational-videos/.

7. Green J, Suresh V, Bittar P, Ledbetter L, Mithani S, Allori A The utilization of video technology in surgical education: a systematic review. J Surg Res 2019; 235: 171-80.

8. Manso-Lorenzo J, Ezquerra A, Burgos-Jiménez ME, Mafokozi J. Análisis del tratamiento de contenido en la creación de audiovisuales educativos. Revista Eureka sobre Enseñanza y Divulgación de las Ciencias 2019; 16: 1601-16.

9. Saurabh S, Gautam S. Modelling and statistical analysis of YouTube's educational videos: a channel Owner's perspective. Computers \& Education 2019; 128: 145-58.

10. Brame CJ. Effective educational videos: principles and guidelines for maximizing student learning from video content. CBE-Life Sciences Education 2016; 15 (es6): 1-6. 